\title{
Extracorporeal pumpless interventional lung assist in clinical practice: determinants of efficacy
}

\author{
T. Müller*, M. Lubnow*, A. Philipp\#, T. Bein`, A. Jeron*, A. Luchner*, L. Rupprecht”, \\ M. Reng ${ }^{+}$, J. Langgartner ${ }^{+}$, C.E. Wrede ${ }^{+}$, M. Zimmermann $^{+}$, D. Birnbaum ${ }^{\#}$, \\ C. Schmid", G.A.J. Riegger* and M. Pfeifer*
}

ABSTRACT: Respiratory acidosis can become a serious problem during protective ventilation of severe lung failure. A pumpless arteriovenous interventional lung assist (iLA) for extracorporeal carbon dioxide removal has been used increasingly to control critical respiratory situations. The present study sought to evaluate the factors determining the efficacy of iLA and calculate its contribution to gas exchange.

In a cohort of 96 patients with severe acute respiratory distress syndrome, haemodynamic parameters, oxygen consumption and carbon dioxide production as well as gas transfer through the iLA were analysed.

The measurements demonstrated a significant dependency of blood flow via the iLA device on cannula size (mean \pm SD $1.59 \pm 0.52 \mathrm{~L} \cdot \mathrm{min}^{-1}$ for 15 French $(\mathrm{Fr}), 1.94 \pm 0.35 \mathrm{~L} \cdot \mathrm{min}^{-1}$ for $17 \mathrm{Fr}$, and $2.22 \pm 0.45 \mathrm{~L} \cdot \mathrm{min}^{-1}$ for $19 \mathrm{Fr}$ ) and on mean arterial pressure. Oxygen transfer capacity averaged $41.7 \pm 20.8 \mathrm{~mL} \cdot \mathrm{min}^{-1}$, carbon dioxide removal was $148.0 \pm 63.4 \mathrm{~mL} \cdot \mathrm{min}^{-1}$. Within two hours of iLA treatment, arterial oxygen partial pressure/inspired oxygen fraction ratio increased significantly and a fast improvement in arterial carbon dioxide partial pressure and $\mathrm{pH}$ was observed.

Interventional lung assist eliminates $\sim \mathbf{5 0} \%$ of calculated total carbon dioxide production with rapid normalisation of respiratory acidosis. Despite limited contribution to oxygen transfer it may allow a more protective ventilation in severe respiratory failure.

KEYWORDS: Acute respiratory distress syndrome, extracorporeal carbon dioxide removal, interventional lung assist, oxygen transfer

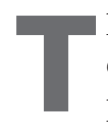

he first successful application of prolonged extracorporeal oxygenation in a young patient with post-traumatic acute respiratory failure was reported more than 35 yrs ago [1]. As technical requirements were very demanding, the use of early extracorporeal membrane oxygenation (ECMO) remained limited to few experienced centres. Two controlled prospective clinical studies in adults with acute respiratory distress syndrome (ARDS) could not demonstrate a significant survival advantage [2,3]. The need for systemic anticoagulation due to the large foreign surface of early devices led to severe bleeding complications in these trials. Consequently, ECMO treatment in adults did not gain wide acceptance. Animal experiments in the 1980s proved that total extracorporeal carbon dioxide removal was possible with a pumpless artery-to-vein shunt [4]. Optimised technical design, especially the development of low-resistance oxygenators, made the use of pumpless devices in humans possible. Early clinical results in small series of patients were encouraging [5-8] and meanwhile interventional lung assist (iLA) has become commercially available. Prospective controlled trials, which are still lacking, have been demanded [9] and have commenced recently.

Low-tidal-volume ventilation is today common practice in the treatment of acute lung failure, often accompanied by hypercapnia and respiratory acidosis. In this context, extracorporeal carbon dioxide elimination could represent an opportunity to avoid potentially dangerous decreases in $\mathrm{pH}$.

Hitherto there have been no investigations analysing systematically the physical and haemodynamic factors that determine the efficacy of iLA in clinical use. It is not known exactly what effective contribution iLA has in carbon dioxide
AFFILIATIONS

*Dept of Internal Medicine II, \#Dept of Cardiothoracic Surgery, "Dept of Anaesthesiology, and +Dept of Internal Medicine I, University Hospital of Regensburg Regensburg, Germany.

CORRESPONDENCE T. Müller

Klinik und Poliklinik für Innere

Medizin II

Universität Regensburg Franz-Josef-Strauss Allee 11 93053 Regensburg Germany Fax: 499419447282 E-mail: thomas.mueller@klinik.uniregensburg.de

Received:

August 112008

Accepted after revision: September 272008

STATEMENT OF INTEREST

A statement of interest for T. Müller can be found at

www.erj.ersjournals.com/misc/ statements.shtml 
removal and oxygen transfer in relation to pulmonary gas transfer. In order to address these questions, the present authors analysed haemodynamic and gas exchange parameters during iLA treatment in patients with ARDS.

\section{METHODS}

\section{Technical data and implantation of iLA}

Between 1996 and 2007, a total of 168 patients were treated with an interventional lung assist device (iLA; NovaLung $\mathrm{GmbH}$, Talheim, Germany) in the present authors' institution (University Hospital of Regensburg, Regensburg, Germany). Technical data about the iLA as well as the process of implantation has been described in detail recently [8]. Some of the dataset used for the present study was included in the previously reported patient outcome data of BEIN et al. [8], therefore the presentation of patient outcome data is not the intention of the present study. In principle, iLA is an artificial arteriovenous shunt with an interposed membrane oxygenator (fig. 1). After ultrasonographic measurement of the femoral artery and the contralateral femoral vein, the cannulae are implanted in Seldinger technique. The size of the arterial cannula has to be smaller than the diameter of the vessel to ensure sufficient peripheral flow. The venous cannula is generally 2 French (Fr) larger to achieve a low flow resistance. The primed oxygenator, which has a total exchange surface of $1.3 \mathrm{~m}^{2}$ and a very low inherent resistance, is then connected to the flushed cannulae. The membrane of the oxygenator is made of polymethylpentene, with the advantage of no plasma leakage. As the whole system is coated with heparin, a strong systemic anticoagulation is not necessary and an activated partial thromboplastin time of 1.5 times normal is generally

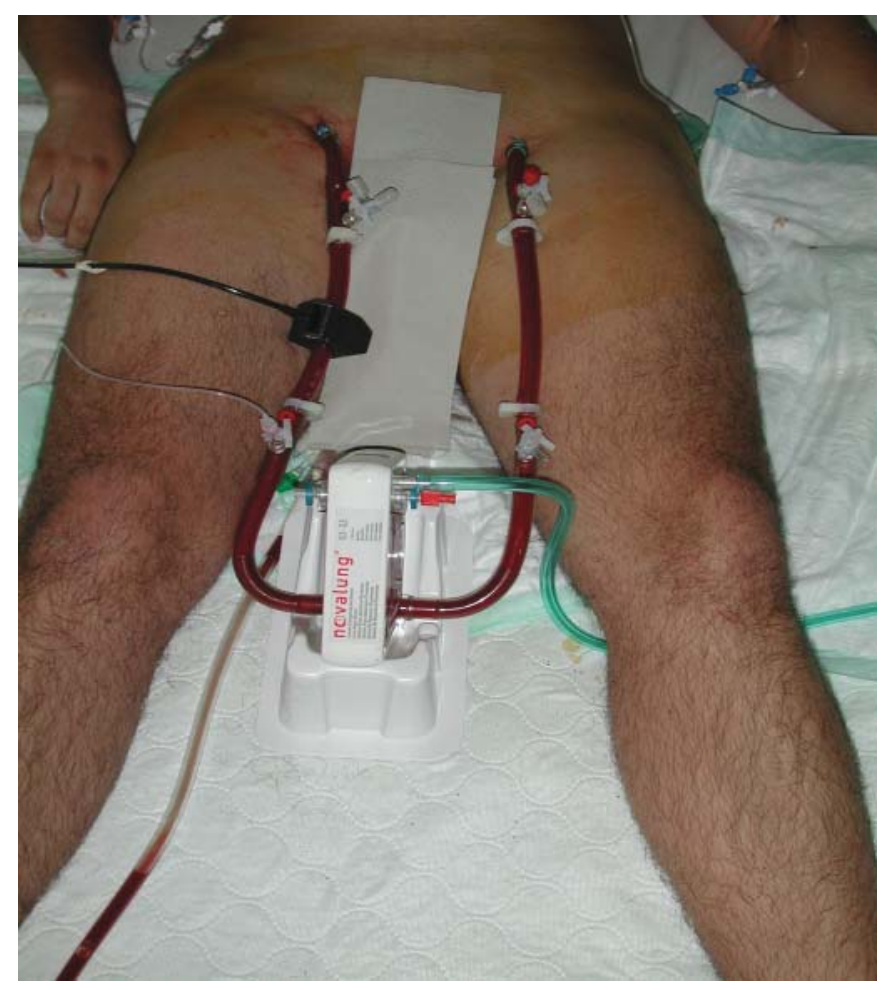

FIGURE 1. The interventional lung assist device (iLA; NovaLung GmbH, Talheim, Germany). sufficient. Oxygen is used as sweep gas, with a flow of up to $12 \mathrm{~L} \cdot \mathrm{min}^{-1}$. Blood flow through the iLA is generated by the arteriovenous pressure difference, so that a pump is not needed. A prerequisite for the employment of iLA is a normal left ventricular function with a mean arterial pressure of $>70 \mathrm{mmHg}$. In patients with cardiac insufficiency or peripheral atherosclerosis, the use of iLA is contraindicated.

\section{Calculation of oxygen and carbon dioxide exchange}

Altogether, 96 out of 168 patients had for clinical reasons been equipped with a pulmonary artery catheter (Swan Ganz Catheter; Edwards Life Sciences, Irvine, CA, USA) and in these patients total body oxygen consumption and carbon dioxide production were calculated. Patients were suffering from severe ARDS (mean $\pm \mathrm{SD}$ arterial oxygen partial pressure $\left(\mathrm{Pa}, \mathrm{O}_{2}\right)$ / inspired oxygen fraction $\left(\mathrm{FI}, \mathrm{O}_{2}\right) 69 \pm 29 \mathrm{mmHg}$, arterial carbon dioxide partial pressure $\left(\mathrm{Pa}_{1} \mathrm{CO}_{2}\right) 66 \pm 25 \mathrm{mmHg}$, positive endinspiratory pressure $38 \pm 6 \mathrm{cmH}_{2} \mathrm{O}$, positive end-expiratory pressure $16 \pm 5 \mathrm{cmH}_{2} \mathrm{O}$, tidal volume $458 \pm 131 \mathrm{~mL}$ ). By measuring the content of oxygen and carbon dioxide before and after the iLA simultaneously, the relative contribution of the iLA to total gas transfer via the lung could be calculated. Measurements were carried out: before iLA start; $2 \mathrm{~h}, 24 \mathrm{~h}$ and $48 \mathrm{~h}$ after iLA implantation; before the cessation of iLA treatment; and 1 day after the end of iLA treatment.

Arterial oxygen content $\left(\mathrm{Ca}, \mathrm{O}_{2}\right)$ was calculated according to the following formula, where $\mathrm{Hb}$ is haemoglobin and $\mathrm{Sa}_{2} \mathrm{O}_{2}$ is arterial oxygen saturation:

$$
\mathrm{Ca}, \mathrm{O}_{2}=\left(\mathrm{Hb} \times 1.31 \times \mathrm{Sa}_{2} \mathrm{O}_{2}\right)+\left(\mathrm{Pa}, \mathrm{O}_{2} \times 0.003\right)
$$

Oxygen delivery capacity $\left(\mathrm{DO}_{2}\right)$ per minute was calculated as follows, where $\mathrm{CO}$ is cardiac output:

$$
\mathrm{DO}_{2}=\mathrm{Ca}_{1} \mathrm{O}_{2} \times \mathrm{CO} \times 10
$$

The oxygen content of mixed venous blood $\left(\mathrm{C}_{\mathrm{v}}, \mathrm{O}_{2}\right)$ was determined in an analogous manner. The difference between arterial and mixed venous oxygen delivery capacity was used to give the oxygen consumption $\left(V^{\prime} \mathrm{O}_{2}\right)$, which is equivalent to the oxygen transfer via the lungs:

$$
V^{\prime} \mathrm{O}_{2}=\left(\mathrm{Ca}_{1} \mathrm{O}_{2}-\mathrm{C}_{\mathrm{v}}, \mathrm{O}_{2}\right) \times \mathrm{CO} \times 10
$$

The oxygen transfer capacity of the iLA (oxygen transferiLA) was calculated by multiplying the difference between oxygen content pre-iLA (i.e. $\mathrm{C}_{\mathrm{a}} \mathrm{O}_{2}$ ) and post-iLA $\left(\right.$ Cpost-iLA, $\left.\mathrm{O}_{2}\right)$ by the blood flow through the iLA (blood flowiLA):

$$
\begin{aligned}
\text { Oxygen transferiLA }= & \left(\text { Cpost-iLA, } \mathrm{O}_{2}-\mathrm{Ca}_{2} \mathrm{O}_{2}\right) \times \text { blood } \\
& \text { flowiLA } \times 10
\end{aligned}
$$

$V^{\prime} \mathrm{O}_{2}$ after iLA implantation was calculated as the combination of natural lung oxygen transfer and membrane lung oxygen transfer:

$$
\begin{aligned}
V^{\prime} \mathrm{O}_{2}= & \left(\mathrm{Ca}_{1} \mathrm{O}_{2}-\mathrm{C}_{\mathrm{V}} \mathrm{O}_{2}\right) \times \mathrm{CO} \times 10+ \\
& \left(\mathrm{C} \text { post-iLA, } \mathrm{O}_{2}-\mathrm{Ca}_{2} \mathrm{O}_{2}\right) \times \text { blood flowiLA } \times 10
\end{aligned}
$$

$\mathrm{CO}$ was determined using the thermodilution method, and the blood flow through the iLA was measured by ultrasound (NovaFlow Ultrasonic Flowmeter; NovaLung $\mathrm{GmbH}$ ). Blood gas analysis was carried out using the Radiometer 700 and 615 analysers (Radiometer, Copenhagen, Denmark). The carbon dioxide content of plasma was calculated by these analysers, 
taking into consideration the Henderson-Hasselbalch equation, by measuring the carbon dioxide partial pressure $\left(\mathrm{PCO}_{2}\right)$ and $\mathrm{pH}$. Like the oxygen content carbon dioxide content was measured at three sites: arterial pre-iLA, post-iLA and in mixed venous blood. With known $\mathrm{CO}$ and blood flow through the iLA, approximate total carbon dioxide production and carbon dioxide removal by the lungs and by the iLA device was calculated.

Approval for the present study was obtained from the Ethics Committee of the University of Regensburg (Regensburg, Germany).

\section{Statistical analysis}

Variables are reported as mean $\pm \mathrm{SD}$, unless otherwise stated, and were compared using paired or unpaired t-tests. Relationships between dependent variables were evaluated by ANOVA on rank and linear regression analysis. A p-value $<0.05$ was considered statistically significant.

\section{RESULTS}

\section{Blood flow through the iLA}

In total, 326 blood flow measurements taken in 96 patients at different times were evaluated: of these, 17 measurements were carried out in arterial 15-Fr cannulae, 175 measurements in arterial 17-Fr cannulae and 134 measurements in arterial 19Fr cannulae. Blood flow through the iLA averaged $1.59 \pm 0.52 \mathrm{~L} \cdot \mathrm{min}^{-1}$ with $15-\mathrm{Fr}$ cannulae. With $17-\mathrm{Fr}$ cannulae, blood flow was $1.94 \pm 0.35 \mathrm{~L} \cdot \mathrm{min}^{-1}$ and with 19 -Fr cannulae it was $2.22 \pm 0.45 \mathrm{~L} \cdot \mathrm{min}^{-1}(\mathrm{p}<0.001)$.

Mean arterial pressure (MAP) was $85.0 \pm 16.6 \mathrm{mmHg}$ and was similar between the three groups with different cannula sizes. In analysing the dependency of blood flow through the iLA upon MAP a linear correlation was found (fig. 2; $r=0.53, p<0.01$ ).

CO was documented simultaneously with 262 iLA blood flow measurements and was $9.1 \pm 2.6 \mathrm{~L} \cdot \mathrm{min}^{-1}$ for all patients (mean norepinephrine dose $1.67 \pm 2.18 \mathrm{mg} \cdot \mathrm{h}^{-1}$ ). Patients with a $19-\mathrm{Fr}$ cannula had a higher $\mathrm{CO}\left(9.6 \pm 2.6 \mathrm{~L} \cdot \mathrm{min}^{-1}\right)$ than patients with a 17 -Fr cannula $\left(8.9 \pm 2.7 \mathrm{~L} \cdot \mathrm{min}^{-1} ; \mathrm{p}<0.05\right)$ or a 15 -Fr cannula $\left(8.5 \pm 2.0 \mathrm{~L} \cdot \mathrm{min}^{-1}\right)$. Figure 3 shows a significant $(\mathrm{r}=0.22$, $\mathrm{p}<0.01$ ), but less obvious correlation between $\mathrm{CO}$ and blood flow through the iLA.

$\mathrm{CO}$ rose from $8.76 \pm 2.6 \mathrm{~L} \cdot \mathrm{min}^{-1}$ before iLA implantation to $9.45 \pm 2.6 \mathrm{~L} \cdot \mathrm{min}^{-1} 2 \mathrm{~h}$ after implantation $(\mathrm{p}<0.001)$. The Horowitz index $\left(\mathrm{Pa}_{1} \mathrm{O}_{2} / \mathrm{FI}, \mathrm{O}_{2}\right)$ increased rapidly from $68.9 \pm 29.9 \mathrm{mmHg}$ before implantation to $93.7 \pm 48.4 \mathrm{mmHg} 2 \mathrm{~h}$ after implantation of the device $(\mathrm{p}<0.001)$.

\section{Effects on oxygen transport}

Taken together over all 326 measurements, oxygen transfer via the iLA averaged $41.7 \pm 20.8 \mathrm{~mL} \cdot \mathrm{min}^{-1}$. During treatment, the oxygen partial pressure $\left(\mathrm{PO}_{2}\right)$ averaged $83 \pm 26 \mathrm{mmHg}$ at the device inlet and $500 \pm 85 \mathrm{mmHg}$ at the outlet. Table 1 summarises the results and factors that influenced oxygen transfer $2 \mathrm{~h}$ after iLA implantation, at day 1 and day 2 and before removal. Oxygen transfer over time decreased, and was calculated at $33.6 \pm 11.7 \mathrm{~mL} \cdot \mathrm{min}^{-1}$ shortly before removal of the iLA ( $\mathrm{p}<0.005$ versus $2 \mathrm{~h}$ after implantation). This reflects both a significantly lower blood flow and a higher $\mathrm{Sa}_{1} \mathrm{O}_{2}$. The oxygen transfer capacity of the iLA depended on $\mathrm{Sa}_{1} \mathrm{O}_{2}(\mathrm{r}=-0.78)$, the

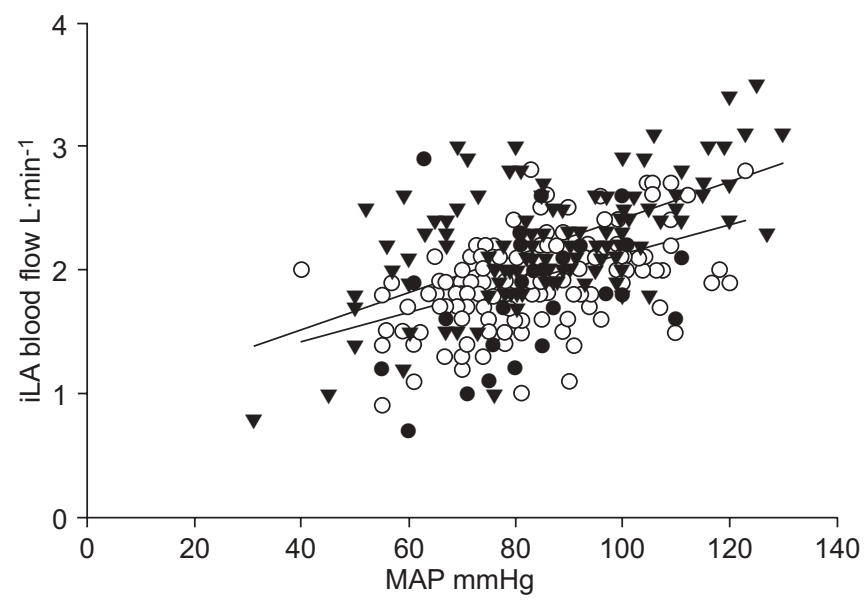

FIGURE 2. Dependency of blood flow through the interventional lung assist device (iLA) on mean arterial pressure (MAP) at different cannula sizes. Regression lines are depicted for 17-French (Fr) and 19-Fr cannulae. $\bullet: 15-F r$ cannulae; $O$ : 17-Fr cannulae; $\boldsymbol{\nabla}$ : 19-Fr cannulae.

blood flow through the device $(\mathrm{r}=0.43)$ and the haemoglobin content of blood $(\mathrm{r}=0.23$; each $\mathrm{p}<0.01$; fig. $4 \mathrm{a}-\mathrm{c})$. A slight correlation was found with sweep gas flow through the device $(\mathrm{r}=0.22$; data not shown). Therefore, oxygen transfer was increased with lower $\mathrm{Sa}_{\mathrm{a}} \mathrm{O}_{2}$, higher blood flow through the system and higher haemoglobin content of blood.

Arterial $\mathrm{DO}_{2}$ rose from $1,024 \pm 338 \mathrm{~mL} \cdot \mathrm{min}^{-1}$ before iLA treatment to $1,187 \pm 350 \mathrm{~mL} \cdot \mathrm{min}^{-1} 2 \mathrm{~h}$ after iLA implantation $(\mathrm{p}<0.001)$. Total $\bar{V}^{\prime} \mathrm{O}_{2}$ was measured 272 times and was $295.4 \pm 97.8 \mathrm{~mL} \cdot \mathrm{min}^{-1}$ for all patients. No significant change was observed in $V^{\prime} \mathrm{O}_{2}$ over time. By comparing $V^{\prime} \mathrm{O}_{2}$ with oxygen transfer through the iLA, the relative contribution of the device to total calculated $V^{\prime} \mathrm{O}_{2}$ was predicted. On average, this contribution was $16.0 \pm 8.3 \%$. Immediately prior to device removal, it had decreased to $10.7 \pm 2.4 \%$.

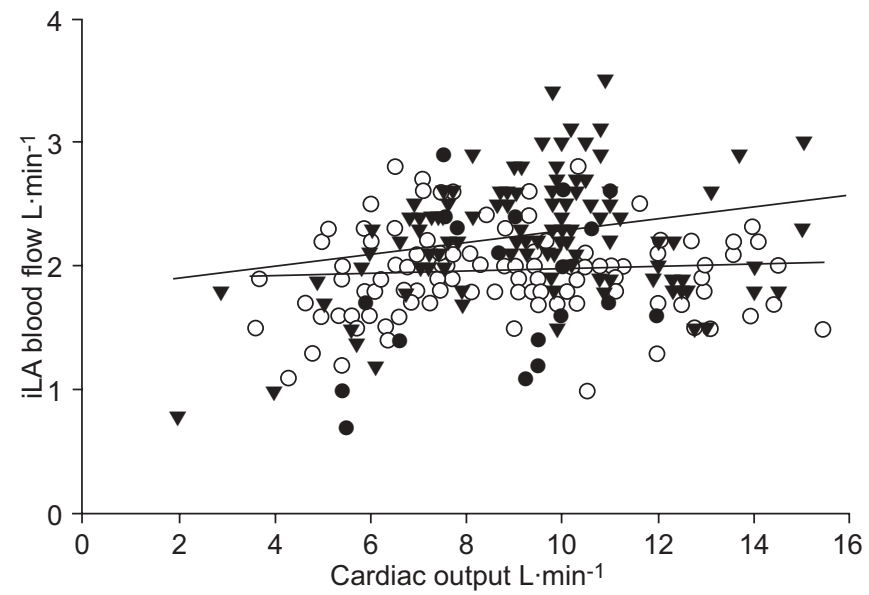

FIGURE 3. Dependency of blood flow through the iLA on cardiac output at different cannula sizes. Regression lines are depicted for 17-French (Fr) and 19-Fr cannulae. - 15-Fr cannulae; 0 : 17-Fr cannulae; $\mathbf{\nabla}$ : 19-Fr cannulae. 


\begin{tabular}{|c|c|c|c|c|c|}
\hline Oxygen transfer $\mathrm{mL} \cdot \mathrm{min}^{-1}$ & $41.7 \pm 20.8$ & $46.1 \pm 26.4$ & $42.7 \pm 13.5$ & $39.4 \pm 14.6$ & $33.6 \pm 11.7^{\#}$ \\
\hline Blood flow $\mathrm{mL} \cdot \mathrm{min}^{-1}$ & $2.05 \pm 0.44$ & $2.11 \pm 0.44$ & $2.16 \pm 0.41$ & $2.09 \pm 0.44$ & $1.95 \pm 0.42^{*}$ \\
\hline MAP mm $\mathrm{Hg}$ & $85.1 \pm 16.5$ & $85.3 \pm 14.7$ & $89.6 \pm 15.4^{*}$ & $87.8 \pm 16.4$ & $84.9 \pm 13.8$ \\
\hline $\mathrm{Sa}, \mathrm{O}_{2} \%$ & $94.2 \pm 6.0$ & $93.4 \pm 6.9$ & $95.0 \pm 3.2^{*}$ & $94.9 \pm 3.7$ & $96.3 \pm 2.4^{\star}$ \\
\hline $\mathrm{PO}_{2}$ post-iLA mmHg & $500 \pm 85$ & $510 \pm 85$ & $506 \pm 78$ & $491 \pm 94$ & $492 \pm 79$ \\
\hline $\mathrm{Do}_{2}$ post-iLA $\mathrm{mL} \cdot \mathrm{min}^{-1}$ & $310 \pm 81$ & $315 \pm 83$ & $332 \pm 76^{*}$ & $320 \pm 81$ & $293 \pm 70^{*}$ \\
\hline
\end{tabular}

Data are presented as mean $\pm \mathrm{SD}$, unless otherwise stated. MAP: mean arterial blood pressure; $\mathrm{Hb}$ : haemoglobin; $\mathrm{Sa}_{2} \mathrm{O}_{2}$ : arterial oxygen saturation; $\mathrm{PO}_{2}$ : oxygen partial pressure; Do 2 : oxygen delivery capacity. *: $p<0.05$ versus $2 \mathrm{~h} ;{ }^{*}: \mathrm{p}<0.005$ versus $2 \mathrm{~h}$

\section{Effects on carbon dioxide elimination and $\mathrm{pH}$}

Before the commencement of iLA treatment, all patients had pronounced hypercapnia, with a $\mathrm{Pa}_{\mathrm{a}} \mathrm{CO}_{2}$ of $66.7 \pm 25 \mathrm{mmHg}$. By $2 \mathrm{~h}$ after iLA implantation, $\mathrm{Pa}_{\mathrm{a}} \mathrm{CO}_{2}$ decreased to $39.5 \pm$ $12.1 \mathrm{mmHg}(\mathrm{p}<0.001)$, and it declined further to $35.8 \pm$ $7.6 \mathrm{mmHg}(\mathrm{p}<0.005) 24 \mathrm{~h}$ later. $\mathrm{Pa}_{1} \mathrm{CO}_{2}$ then remained stable during continuation of iLA treatment and increased to $49.8 \pm 14.7 \mathrm{mmHg}$ after removal of the iLA $(\mathrm{p}<0.001)$.

Taking all measurements during iLA treatment $(n=243)$ together, $\mathrm{PCO}_{2}$ averaged $37.5 \mathrm{mmHg}$ at the iLA inlet and $23.5 \mathrm{mmHg}$ at the outlet. The device removed $148.0 \pm$ $63.4 \mathrm{~mL} \cdot \mathrm{min}^{-1}$ carbon dioxide, which is equal to $\sim 50 \%$ of the calculated total carbon dioxide production of $291 \pm 124 \mathrm{~mL} \cdot \mathrm{min}^{-1}$. The capacity of the iLA to remove carbon dioxide increased with higher $\mathrm{Pa}_{\mathrm{a}} \mathrm{CO}_{2}(\mathrm{r}=0.34, \mathrm{p}<0.01)$, higher sweep gas flow $(r=0.27, p<0.01)$ and higher blood flow through the device $(\mathrm{r}=0.23, \mathrm{p}<0.01$; fig. $5 \mathrm{a}-\mathrm{c})$. No correlation was found to haemoglobin content of blood (data not shown). A carbon dioxide elimination of $135.6 \pm 30.2 \mathrm{~mL} \cdot \mathrm{min}^{-1}$ was seen with 15 Fr cannulae, versus $144.1 \pm 68.6 \mathrm{~mL} \cdot \mathrm{min}^{-1}$ with 17 -Fr cannulae, and $154.3 \pm 58.1 \mathrm{~mL} \cdot \mathrm{min}^{-1}$ with $19-\mathrm{Fr}$ cannulae $(\mathrm{p}<0.001)$.
The reduction of $\mathrm{Pa}_{\mathrm{a}} \mathrm{CO}_{2}$ resulted in a rapid and sustained normalisation of respiratory acidosis. The $\mathrm{pH}$ rose within $2 \mathrm{~h}$ after iLA implantation, from $7.24 \pm 0.13$ to $7.41 \pm 0.12$ ( $\mathrm{p}<0.001$; fig. 6). During extracorporeal carbon dioxide removal, $\mathrm{pH}$ remained stable. After termination of iLA, $\mathrm{pH}$ fell significantly to $7.36 \pm 0.09(\mathrm{p}<0.001)$.

\section{DISCUSSION}

The current study is the first to systematically investigate the efficacy of iLA on oxygen transfer capacity and carbon dioxide removal in a large human study population with severe ARDS. It provides detailed information regarding the factors that influence iLA performance and supports the use of iLA as a highly effective method in severe lung injury with hypercapnia and respiratory acidosis.

\section{Blood flow through the iLA}

Blood flow through the iLA depends on both the total inherent resistance of the device and on the pressure difference across the system. The flow resistance of the oxygenator is low and causes a pressure drop of $\sim 10 \mathrm{mmHg}$ at a blood flow of $2 \mathrm{~L} \cdot \mathrm{min}^{-1}$. Thus the flow resistance of the cannulae is the
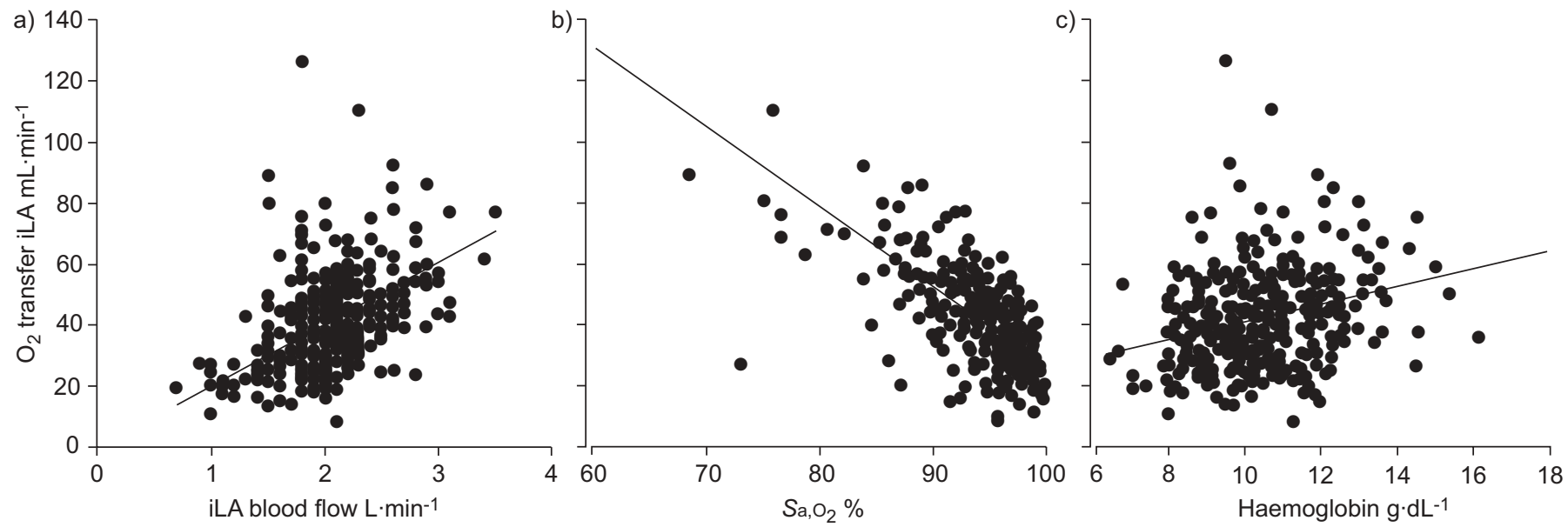

FIGURE 4. The influence of a) blood flow, b) arterial oxygen saturation $\left(\mathrm{Sa}, \mathrm{O}_{2}\right)$ and c) haemoglobin content on oxygen transfer through the interventional lung assist device (iLA). 


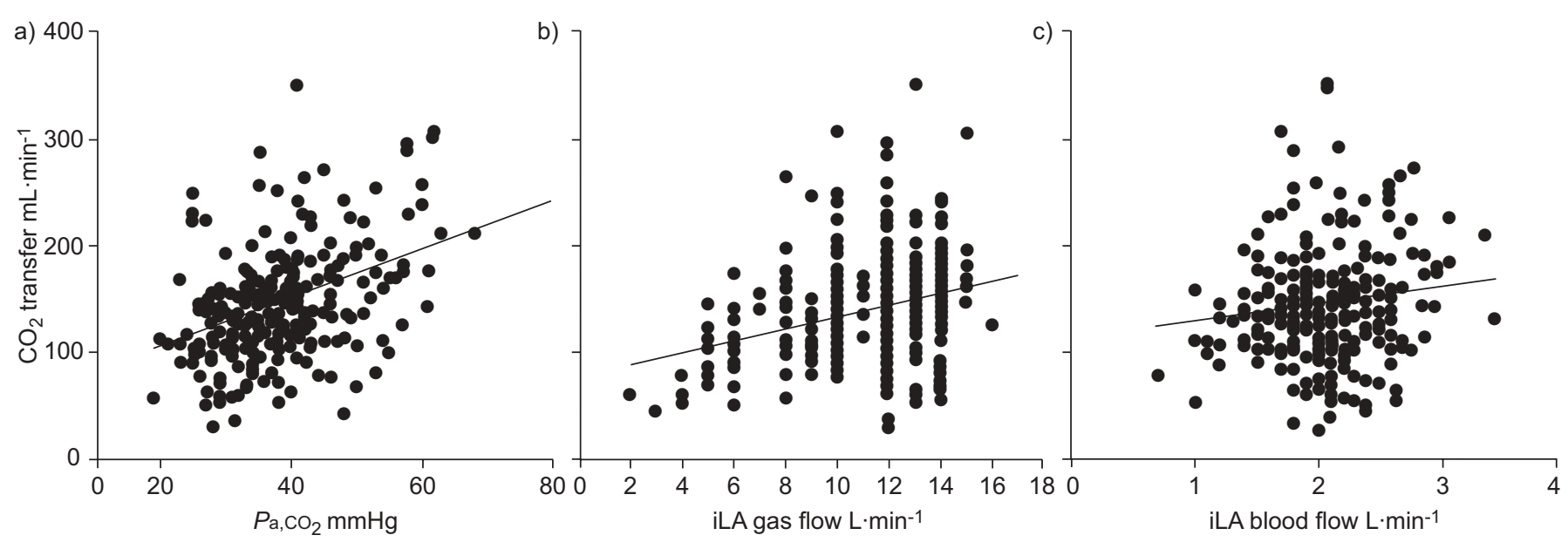

FIGURE 5. The influence of a) arterial carbon dioxide tension $\left(\mathrm{Pa}_{1} \mathrm{CO}_{2}\right)$, b) sweep gas flow and c) blood flow on carbon dioxide transfer through the interventional lung assist device (iLA).

predominant factor of total resistance of the device. According to the Hagen-Poiseuille equation, blood flow is most strongly influenced by the diameter of the cannula, where $\Delta \mathrm{p}$ is pressure difference, $r$ is the radius of the cannula, 1 is the length of the cannula and $\eta$ is viscosity:

$$
\text { blood flow }=\left(\pi \times \Delta \mathrm{p} \times \mathrm{r}^{4}\right) /(8 \times 1 \times \eta)
$$

The present in vivo measurements confirmed these considerations as well as animal data previously published [10, 11]. A 2Fr increase in cannula size resulted in an additional flow of $\sim 300 \mathrm{~mL} \cdot \mathrm{min}^{-1}$. This means that using a $15-\mathrm{Fr}$ arterial cannula, a blood flow of $\sim 1.6 \mathrm{~L} \cdot \mathrm{min}^{-1}$ can be achieved at an MAP of $85 \mathrm{mmHg}$, versus $\sim 1.9 \mathrm{~L} \cdot \mathrm{min}^{-1}$ using a $17-\mathrm{Fr}$ cannula and $\sim 2.2 \mathrm{~L} \cdot \mathrm{min}^{-1}$ using a 19-Fr cannula.

The second important factor for blood flow through the device is the difference between pressure before (MAP) and after the system (central venous pressure (CVP)). As CVP fluctuates within close limits, MAP is the decisive variable for blood flow and a strong correlation was demonstrated between MAP and blood flow through the iLA. In clinical practice, MAP is the

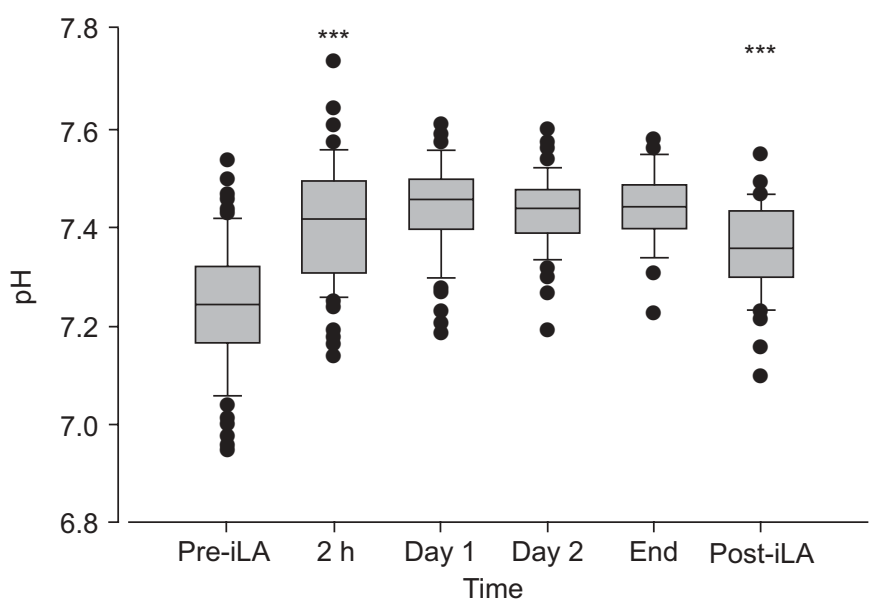

FIGURE 6. Arterial pH before, during and after interventional lung assist (iLA) treatment. ${ }^{* * *}: \mathrm{p}<0.001$ only relevant parameter for iLA flow that can be influenced at a given cannula size.

CO per se is not important in determining blood flow through the iLA. On average, blood flow amounted to $20 \%$ of CO with $15-\mathrm{Fr}$ cannulae and up to $25 \%$ of CO with $19-\mathrm{Fr}$ cannulae. Comparable numbers have been found in animal experiments [12, 13]. In patients with lower $\mathrm{CO}$ and normal MAP due to high systemic vascular resistance, a higher proportion of $\mathrm{CO}$ is diverted through the iLA, which may amount to $>30 \%$ of CO (fig. 7). In most patients, a significant increase in $\mathrm{CO}$ after the start of iLA was observed. This can be explained by two mechanisms: first, the creation of an artificial low resistance arteriovenous shunt; and secondly, rapid correction of acidosis resulting in improved vasotonus and possibly cardiac pump function.

\section{Effects on oxygen transport}

The average iLA oxygen transfer capacity of $42 \mathrm{~mL} \cdot \mathrm{min}^{-1}$ measured in the current patients matches well with animal data presented by ZICK et al. [12] and BREDERLAU et al. [14]. Another study mentioned an oxygen transfer rate of up to

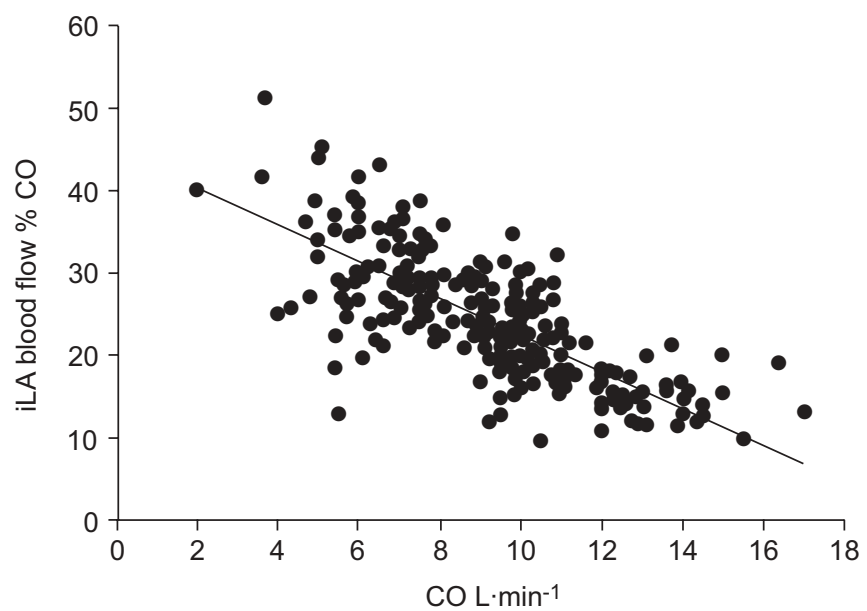

FIGURE 7. Blood flow through the interventional lung assist device (iLA; expressed as \% of cardiac output (CO)) and total CO. $r=-0.74, p<0.01$. 
$225 \mathrm{~mL} \cdot \mathrm{min}^{-1}$ [15], which does not correspond to the present results and is physically not plausible. The oxygen transfer capacity of the iLA is limited mainly by the fact that arterial blood, already well oxygenated, is fed into the device, and therefore only a small additional amount of oxygen can be bound to haemoglobin.

Most studies in humans have described a significant rise in $\mathrm{Pa}_{1} \mathrm{O}_{2}$ after implementation of iLA treatment $[6-8,16-18]$. The patients evaluated in the current study had a $\mathrm{Pa}, \mathrm{O}_{2} / \mathrm{FI}_{1} \mathrm{O}_{2}$ ratio of $69 \mathrm{mmHg}$ before iLA treatment, which increased to $94 \mathrm{mmHg}$ within $2 \mathrm{~h}(\mathrm{p}<0.001)$. This rise in $\mathrm{Pa}_{2} \mathrm{O}_{2}$, according to the law of Dalton, is caused mainly by a reduction of alveolar $\mathrm{PCO}_{2}$ and a concomitant increase in alveolar $\mathrm{PO}_{2}$. Because $\mathrm{Pa}_{1} \mathrm{O}_{2}$ is an inaccurate parameter for oxygen supply, the current authors calculated the arterial oxygen delivery, $\mathrm{DO}_{2}$. The rise in $\mathrm{DO}_{2}$ from $1,024 \mathrm{~mL} \cdot \mathrm{min}^{-1}$ before iLA treatment to $1,187 \mathrm{~mL} \cdot \mathrm{min}^{-1} 2 \mathrm{~h}$ after iLA implantation $(\mathrm{p}<0.001)$ was caused by a small increase in $\mathrm{CO}$ and a higher $\mathrm{Ca}, \mathrm{O}_{2}$. However, it is important to consider that part of $\mathrm{CO}$ is diverted through the artificial arterio-venous shunt of the iLA and therefore it does not participate in peripheral perfusion. The effective $\mathrm{DO}_{2}$, which is available to supply the organism, may even be smaller than that prior to iLA implantation. This is to be expected particularly in patients with a low $\mathrm{CO}$ and high-dose vasopressors, when a comparatively high proportion of $\mathrm{CO}$ will flow through the iLA (fig. 7). In patients with reduced $\mathrm{CO}$, therefore, iLA therapy is probably not indicated. BRUNSTON et al. [19] analysed the perfusion of organs at different blood flow rates through a pumpless extracorporeal membrane oxygenator using colored microspheres and reported a mild reduction in end-organ perfusion. However at a maximal shunt flow of $25 \%$ of $\mathrm{CO}$, a reduced perfusion of the cerebrum of up to $26 \%$ and of skeletal muscle of up to $43 \%$ was observed.

The total $V^{\prime} \mathrm{O}_{2}$ of the current patients was calculated at $295 \mathrm{~mL} \cdot \mathrm{min}^{-1}$. This is comparable with earlier studies in critically ill patients $[20,21]$. At the beginning of extracorporeal therapy, oxygen transfer through the iLA accounted for $16 \%$ of $V^{\prime} \mathrm{O}_{2}$. At the end of iLA treatment, oxygen transfer amounted to $11 \%$ of $V^{\prime} \mathrm{O}_{2}$. These results are in accordance with animal experiments, which found the relative share of iLA treatment of total $V^{\prime} \mathrm{O}_{2}$ to be between $12.5 \%$ and $19.5 \%[12,14]$. However, as the current authors only carried out a blood phase calculation of oxygen consumption and carbon dioxide production, the metabolic rate of the lung itself was not taken into consideration. Therefore, the relative numbers may be an overestimation.

After implementation of iLA treatment mixed venous oxygen saturation rose within $2 \mathrm{~h}$ from $62 \%$ to $74 \%(\mathrm{p}<0.001)$. The consequences of this increase of oxygen supply in the pulmonary artery, in combination with a rapid normalisation of the $\mathrm{pH}$, have not yet been investigated in humans.

\section{Effects on carbon dioxide elimination}

GATTINONI et al. [22] demonstrated 20 yrs ago using a pumpdriven device that extracorporeal carbon dioxide removal can allow a more protective ventilation, albeit they were unable to show a survival benefit. As the necessary blood flow for clinically significant extracorporeal carbon dioxide removal is relatively small, the application of a pumpless arterio-venous system with a low inherent flow resistance is possible.
BRUNSTON and coworkers $[10,23]$ proved that near-total carbon dioxide elimination can be achieved with such a system in sheep. In the present patients, a rapid initial decrease of $\mathrm{Pa}, \mathrm{CO}_{2}$ was seen, from $67 \mathrm{mmHg}$ pre-iLA to $40 \mathrm{mmHg} 2 \mathrm{~h}$ after iLA implementation. During the following $24 \mathrm{~h}$ a further, smaller reduction in $\mathrm{Pa}, \mathrm{CO}_{2}$ was observed. This is probably explained by the transport and storage kinetics of carbon dioxide, which is transported in physical solution, protein bound and in the form of bicarbonate. The physically dissolved proportion, which can be measured as $\mathrm{Pa}_{1} \mathrm{CO}_{2}$, can be eliminated quickly. However, the predominant portion of carbon dioxide is stored and transported as bicarbonate ions, which have to be dissociated within red blood cells in the presence of carbonic anhydrase. Due to the liberation of bicarbonate from slow compartments, it takes several hours until the carbon dioxide level reaches a new stable equilibrium.

This biphasic elimination kinetic of carbon dioxide is mirrored in several clinical reports $[8,16,24,25]$. The quantity of carbon dioxide removed through the iLA in the current patients, was $148 \mathrm{~mL} \cdot \mathrm{min}^{-1}$, which accounted for $\sim 50 \%$ of total calculated carbon dioxide production. CONRAD et al. [26] and ZWISCHENBERGER et al. [24] reported in their small clinical trials on eight and five patients, respectively, complete and $70 \%$, respectively, removal of carbon dioxide with the use of an Affinity oxygenator (Medtronic, Minneapolis, MN, USA). This oxygenator has a surface area of $2.5 \mathrm{~m}^{2}$, which is almost double the size of the Novalung oxygenator. With arterial 12-Fr cannulae a maximal blood flow of $1 \mathrm{~L} \cdot \mathrm{min}^{-1}$ was reached through the device, producing a carbon dioxide removal of $>100 \mathrm{~mL} \cdot \mathrm{min}^{-1}$, measured at the outlet of the sweep gas flow and in the exhaled ventilator gas. This method of determining $\mathrm{CO}_{2}$ removal differs from that of the present study, in which the carbon dioxide content of blood was calculated before and after the iLA and the lungs, respectively. Using the Henderson-Hasselbalch equation, the carbon dioxide content is calculated by the blood gas analyser with known $\mathrm{pH}$, bicarbonate, haemoglobin and $\mathrm{PCO}_{2}$. The calculated total carbon dioxide production of $291 \mathrm{~mL} \cdot \mathrm{min}^{-1}$ in the current patients corresponds well to the measured $V^{\prime} \mathrm{O}_{2}$ of $296 \mathrm{~mL} \cdot \mathrm{min}^{-1}$. In animal studies, an extracorporeal carbon dioxide elimination of $62-104 \mathrm{~mL} \cdot \mathrm{min}^{-1}$ in pigs [13] and up to $120 \mathrm{~mL} \cdot \mathrm{min}^{-1}$ in sheep $[23,27]$ has been reported. The amount of removed carbon dioxide depends closely on $\mathrm{Pa}_{\mathrm{a}} \mathrm{CO}_{2}$ and sweep gas flow according to the current data. CONRAD et al. [26] observed in their analysis of contributing factors to carbon dioxide transfer a significant regression to $\mathrm{Pa}_{\mathrm{a}} \mathrm{CO}_{2}, \mathrm{pH}$, sweep gas flow and blood flow through the device.

Extracorporeal carbon dioxide removal resulted in a rapid improvement of respiratory acidosis. A retrospective clinical trial has demonstrated that with rising $\mathrm{pH}$ the dose of vasopressors could be diminished and the invasiveness of mechanical ventilation was decreased [8]. In large-animal ARDS models, extracorporeal carbon dioxide removal enabled less invasive ventilation with reduced levels of inflammatory cytokines [28, 29].

\section{Conclusion}

In conclusion, the present authors found that an average extracorporeal carbon dioxide elimination of $\sim 50 \%$ of total production is possible with the interventional lung assist 
device in patients with acute respiratory distress syndrome. To achieve this, the use of arterial cannulae of 15- or 17-French size is sufficient. Larger cannulae may cause an undesirably large arteriovenous shunt fraction and carry a higher risk of vascular complications, as has been reported previously [8]. In some patients with low body weight and less severe respiratory acidosis, even $13-$ French cannulae may be suitable, but these could possibly result in earlier occlusion of the oxygenator due to lower blood flow. A rapid decrease in arterial carbon dioxide partial pressure and normalisation of $\mathrm{pH}$ may allow a more protective ventilation with even lower tidal volumes and therefore possibly a reduction of ventilatorinduced lung injury. Interventional lung assist does improve arterial oxygenation and transfers $\sim 45 \mathrm{~mL} \cdot \mathrm{min}^{-1}$ of oxygen; however, this does not necessarily mean that oxygen delivery is increased as well. Therefore, according to the current data, interventional lung assist should probably not be used in patients with the most severely impaired oxygenation or in patients with reduced cardiac output. Whether survival in acute respiratory failure can be improved with the implementation of interventional lung assist as a method to reduce invasiveness of ventilation needs further study through controlled clinical trials.

\section{REFERENCES}

1 Hill JD, O’Brien TG, Murray JJ, et al. Prolonged extracorporeal oxygenation for acute post-traumatic respiratory failure (shock-lung syndrome). Use of the Bramson membrane lung. N Engl J Med 1972; 286: 629-634.

2 Zapol WM, Snider MT, Hill JD, et al. Extracorporeal membrane oxygenation in severe acute respiratory failure. A randomised prospective study. JAMA 1979; 242: 2193-2196.

3 Morris AH, Fallace CJ, Menlove RL, et al. Randomized clinical trial of pressure-controlled inverse ratio ventilation and extracorporeal $\mathrm{CO}_{2}$ removal for adult respiratory distress syndrome. Am J Respir Crit Care Med 1994; 149: 295-305.

4 Barthelemy R, Galetti PM, Trudell LA, et al. Total extracorporeal $\mathrm{CO}_{2}$ removal in a pumpless artery-to-vein shunt. Trans Am Soc Artif Intern Organs 1982; 28: 354-358.

5 Philipp A, Behr R, Reng M, Kaiser M, Birnbaum D. Pumpless extracorporeal lung assist. J Extra-Corporeal Technol 1998; 30: 38-41.

6 Reng M, Philipp A, Kaiser M, Gruene S, Schoelmerich J. Pumpless extracorporeal lung assist and adult respiratory distress syndrome. Lancet 2000; 356: 219-220.

7 Liebold A, Reng CM, Philipp A, Pfeifer M, Birnbaum DE. Pumpless extracorporeal lung assist - experience with the first 20 cases. Eur J Cardiothorax Surg 2000; 17: 608-613.

8 Bein $\mathrm{T}$, Weber F, Philipp A, et al. A new pumpless extracorporeal interventional lung assist in critical hypoxemia/hypercapnia. Crit Care Med 2006; 34: 1372-1377.

9 Morris AH. Extracorporeal support and patient outcome: credible causality remains elusive. Crit Care Med 2006; 34: 1551-1552.

10 Brunston RL, Tao W, Bidani A, Cardenas VJ, Traber DL, Zwischenberger JB. Determination of low blood flow limits for arteriovenous carbon dioxide removal. ASAIO J 1996; 42: M845-M849.
11 Zhou X, Loran DB, Wang D, Hyde BR, Lick SC, Zwischenberger JB. Seventy-two hour gas exchange performance and hemodynamic properties of NOVALUNG iLA as a gas exchanger for arteriovenous carbon dioxide removal. Perfusion 2005; 20: 303-308.

12 Zick G, Frerichs I, Schädler D, et al. Oxygenation effect of interventional lung assist in a lavage model of acute lung injury: a prospective experimental study. Crit Care 2006; 10: R56.

13 De Somer F, Van Belleghem Y, Foubert L, et al. Feasibility of a pumpless extracorporeal respiratory assist device. J Heart Lung Transplant 1999; 18: 1014-1017.

14 Brederlau J, Muellenbach R, Kredel M, et al. The contribution of arterio-venous extracorporeal lung assist to gas exchange in a porcine model of lavage-induced acute lung injury. Perfusion 2006; 21: 277-284.

15 Iglesias $M$, Jungebluth $\mathrm{P}$, Sibila $\mathrm{O}$, et al. Experimental safety and efficacy evaluation of an extracorporeal pumpless artificial lung in providing respiratory support through the axillary vessels. J Thorac Cardiovasc Surg 2007; 133: 339-345.

16 Fischer F, Simon AR, Welte $\mathrm{T}$, et al. Bridge to lung transplantation with the novel pumpless interventional lung assist device NovaLung. J Thorac Cardiovasc Surg 2006; 131: 719-723.

17 Bein T, Prasser C, Philipp A, et al. Pumpenfreie extrakorporale Lungenunterstützung mit arteriovenösem Shunt beim schweren akuten Lungenversagen des Erwachsenen. Anaesthesist 2004; 53: 813-819.

18 Zimmermann M, Bein T, Philipp A, et al. Interhospital transportation of patients with severe lung failure on pumpless extracorporeal lung assist. Br J Anaesth 2006; 96: 63-66.

19 Brunston RL, Tao W, Bidani A, Traber DL, Zwischenberger JB. Organ blood flow during arteriovenous carbon dioxide removal. ASAIO J 1997; 43: M821-M824.

20 Hayes MA, Timmins AC, Yau E, Palazzo M, Hinds CJ, Watson D. Elevation of systemic oxygen delivery in the treatment of critically ill patients. N Engl J Med 1994; 330: 1717-1722.

21 Gattinoni L, Brazzi L, Pelosi P, et al. A trial of goalorientated hemodynamic therapy in critically ill patients. $N$ Engl J Med 1995; 333: 1025-1032.

22 Gattinoni L, Pesenti A, Mascheroni D, et al. Low-frequency positive-pressure ventilation with extracorporeal $\mathrm{CO}_{2}$ removal in severe acute respiratory failure. JAMA 1986; 256: 881-886.

23 Brunston RL, Zwischenberger JB, Tao W, Cardenas VJ, Traber DL, Bidani A. Total arteriovenous $\mathrm{CO}_{2}$ removal: simplifying extracorporeal support for respiratory failure. Ann Thorac Surg 1997; 64: 1599-1605.

24 Zwischenberger JB, Conrad SA, Alpard SK, Grier LR, Bidani A. Percutaneous extracorporeal arteriovenous $\mathrm{CO}_{2}$ removal for severe respiratory failure. Ann Thorac Surg 1999; 68: 181-187.

25 Elliot SC, Paramasivam K, Oram J, Bodenham AR, Howell SJ, Mallick A. Pumpless extracorporeal carbon dioxide removal for life-threatening asthma. Crit Care Med 2007; 35: 945-948.

26 Conrad SA, Zwischenberger JB, Grier LR, Alpard SK, Bidani A. Total extracorporeal arteriovenous carbon dioxide removal in acute respiratory failure: a phase I clinical study. Intensive Care Med 2001; 27: 1340-1351. 
27 Zwischenberger JB, Alpard SX, Tao W, Deyo D, Bidani A. Percutaneous extracorporeal arteriovenous carbon dioxide removal improves survival in respiratory distress syndrome: a prospective randomised outcomes study in adult sheep. J Thorac Cardiovasc Surg 2001; 121: 542-552.

28 Schmalstieg FC, Chow J, Savage C, Rudloff HE, Palkowetz KH, Zwischenberger JB. Interleukin-8, aquaporin-1, and inducible nitric oxide synthase in smoke and burn injured sheep treated with percutaneous carbon dioxide removal. ASAIO J 2001; 47: 365-371.

29 Vertrees RA, Nason R, Hold MD, et al. Smoke/burn injuryinduced respiratory failure elicits apoptosis in ovine lungs and cultured lung cells, ameliorated with arteriovenous $\mathrm{CO}_{2}$ removal. Chest 2004; 125: 1472-1482. 